\title{
FLAVONOL PROFILES FOR VARIETAL DIFFERENTIATION BETWEEN CARMÉNÈRE AND MERLOT WINES PRODUCED IN CHILE: HPLC AND CHEMOMETRIC ANALYSIS
}

\author{
C.VERGARA I , D. VON BAER ${ }^{1 *}$, C. MARDONES ${ }^{l}$, L. GUTIÉRREZ ${ }^{2}$, I. HERMOSÍN-GUTIÉRREZ \\ N. CASTILLO-MUNOZZ
}

\author{
${ }^{I}$ Departamento de Análisis Instrumental, Facultad de Farmacia, Universidad de Concepción, Concepción, Chile \\ ${ }^{2}$ Departamento de Estadística, Facultad de Matemáticas, Pontificia Universidad Católica de Chile, Santiago, Chile \\ ${ }^{3}$ Universidad de Castilla-La Mancha, Escuela Universitaria de Ingeniería Técnica Agrícola, Ronda de Calatrava 7, 13071 Ciudad Real, España \\ (Received: June 30, 2010 - Accepted: June 24, 2011)
}

\begin{abstract}
Wine differentiation is an important issue for the Chilean winemaking industry, especially for the Carménère variety, which was rediscovered in this country around 20 years ago. Authentication parameters are required for this wine due to its frequent confusion with Merlot. The concentration of anthocyanins, shikimic acid, and the principal flavonols found in wine allowed some varietal differentiation between Carménère and Merlot wines. Myricetin and quercetin are the most concentrated flavonols in wine in which they are present in free and conjugated forms. These compounds are responsible for important wine antioxidant properties.

In the present work, using only the concentrations of free and conjugated quercetin and myricetin, differentiation between Carménère and Merlot varieties was better achieved. Flavonol profiles of wine produced in Chile were studied with HPLC-DAD-ESI-MS ${ }^{\mathrm{n}}$. An overview of the concentration range of flavonols present in 248 Chilean red wines is presented, finding that the mean concentration of the sum of total myricetin and total quercetin were higher in Carménère $\left(81.5 \mathrm{mgL}^{-1}\right)$ and Merlot $\left(78.9 \mathrm{mgL}^{-1}\right)$ than in Cabernet Sauvignon $\left(53.9 \mathrm{mgL}^{-1}\right)$ wines. These mean levels were higher than the majority of the concentrations reported in the literature. The chemometric analysis shows that the ratio of total quercetin/total myricetin combined with the concentration of free myricetin allowed the varietal differentiation between Carménère and Merlot wines.
\end{abstract}

Keywords: Carménère, Merlot, myricetin, PCA, quercetin, varietal differentiation, wine.

\section{INTRODUCTION}

Varietal differentiation of wines is relevant to the winemaking industry in Chile, especially for the export wines. The three main red wine varieties produced in Chile are Cabernet Sauvignon, Merlot and Carménère. Carménère is especially important because it practically disappeared in mid- $19^{\text {th }}$ century in most countries due to Phylloxera, although it was rediscovered in Chile around 20 years $\mathrm{ago}^{1-3}$. Additionally, since all vineyards planted with Carménère grape variety in Chile were previously considered as Chilean Merlot, some misclassification still occurs. Presently, since over 8,800 hectares are planted in Chile with this variety and it is promoted as Chile's own signature grape ${ }^{4}$, appropriate analytical and chemometric tools of varietal authentication Carménère are required.

Varietal differentiation of Cabernet Sauvignon from Merlot and Carménère wines produced in Chile can be achieved using the ratio of acetylated and coumaroylated anthocyanins alone $e^{5-7}$ or in combination with shikimic acid concentration $^{8,9}$. Using the proportion of nine monomeric anthocyanins in combination with the ratio between total quercetin and total myricetin concentration, it is possible to improve the varietal differentiation between Carménère and Merlot ${ }^{9}$.

Flavonols are one of the groups of compounds with antioxidant properties, which are transferred from the grape skin to the wine during maceration. They are present in wine as aglycones (Fig. 1 A) and in glycosilated form. In Vitis vinifera, the most common conjugated flavonols are 3-O-glycosides, such as glucoside, glucuronoside, galactoside, and rutinoside (Fig. 1B). This glycosilations are catalysed by glycosyltransferases, which transfer glycosyl group nucleoside diphosphate-activated sugars (UDP-sugars) to acceptor aglycones, as ilustrated with the example of Fig. $2^{10,11,12}$. Quercetin and myricetin and their conjugated derivates have the highest concentration in wines ${ }^{13}$ and they are the most important due to the antioxidant power in cellular assays. This is especially true for quercetin ${ }^{14}$, which also has been reported to have anticarcinogenic effects ${ }^{15,16}$. McDonald et al. ${ }^{17}$ determined these antioxidants in 65 commercial wine samples of different grape varieties coming from several parts of the world, reporting that the highest concentrations were found in some wines produced in Chile. However, in that case, only 6 Chilean samples of Cabernet Sauvignon, 3 of Merlot and 2 of Pinot Noir were analysed. In the present work, the concentration of flavonols was determined in 248 Cabernet Sauvignon, Merlot and Carménère wines produced in Chile between the Maipo and the Bio-Bío Valleys in order to determine the flavonol concentration range in these varieties of Chilean wines.

The aim of this work was to evaluate the differentiation power of flavonol profiles, using chemometric tools, without considering more classical parameters such as anthocyanin profiles and shikimic acid concentration. An overview of the concentration range of the principal flavonols in red wines produced in Chile is discussed from the perspective of their health benefits.

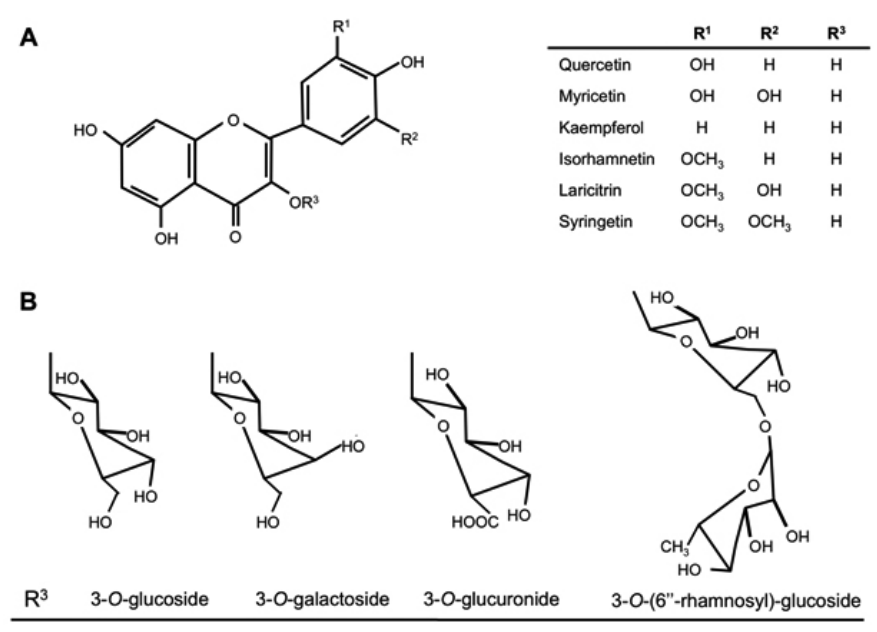

Figure 1: Chemical structures of main free and glycosilated flavonols in wine.

\section{Materials and methods}

All solutions were prepared in $18 \mathrm{MW}$ de-ionized water from a Millipore Milli-Q water purification system. HPLC grade acetonitrile and methanol were purchased from J.T.Baker (Phillipsburg, USA). Trifluoroacetic acid, hydrochloric acid and diethyldithiocarbamate were obtained from Merck (Darmstadt, Germany). Flavonol standards were obtained from SIGMA (St. Louis, USA).

All wine samples came directly from wineries located in the Casablanca, Maipo, Rapel, Colchagua, Curicó, Maule, Itata and Bío- Bío Valleys in Chile. Vinification was made at production scale and samples were taken after malolactic fermentation and before blending. No commercial bottled wine samples were included in the study. The producer declared the grape variety. In 40 samples of Carménère, 35 of Merlot and 108 of Cabernet Sauvignon, total and conjugated flavonols were determined. Additionally, in 18 samples of Carménère and 15 of Merlot, free flavonols were determined. 
<smiles></smiles>
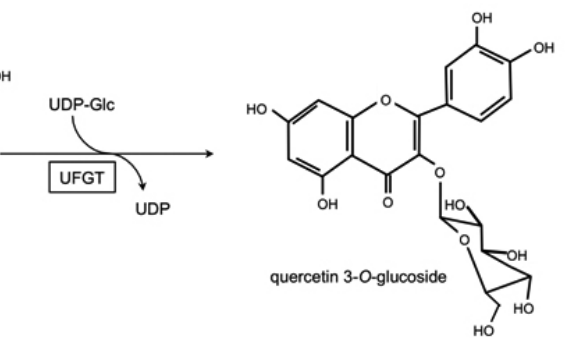

Figure 2: The reaction catalysed by Vitis vinifera UDPGlucose:flavonoid 3-O-glycosyltransferase (UFGT) is the addition of glucose, from a UDPglucose donor to the 3-O position of quercetin.

The identification of wine flavonols was performed in a HPLC with Diode Array Detection and Electrospray Ionization Multiple Mass Spectrometry (HPLC-DAD-ESI-MS ${ }^{\mathrm{n}}$ ). The analyses were performed on an Agilent 1100 Series system (Agilent, Germany), equipped with DAD (G1315B) and LC/ MSD Trap VL (G2445C VL) electrospray ionization mass spectrometer (ESI$\mathrm{MS}^{\mathrm{n}}$ ) system, and coupled to an Agilent Chem Station (version B.01.03) dataprocessing station. The mass spectra data were processed with the Agilent LC/MS Trap software (version 5.3). The wine samples, after filtration $(0.20$ $\mathrm{mm}$, polyester membrane, Chromafil PET 20/25, Macherey-Nagel, Düren, Germany), were injected $(50 \mu \mathrm{L})$ on a reversed-phase Zorbax Eclipse XDB-C18 column $(4.6$ x $250 \mathrm{~mm} ; 5 \mathrm{~mm}$ particle; Agilent, Germany) and thermostated at $40{ }^{\circ} \mathrm{C}$. MS parameters: positive ion mode, dry gas: $\mathrm{N}_{2}, 11 \mathrm{~L}$ min, dry temperature: $325^{\circ} \mathrm{C}$, nebulizer: $60 \mathrm{psi}$, capillary: $-2500 \mathrm{~V}$, capillary exit offset: $70 \mathrm{~V}$, end plate offset: $-500 \mathrm{~V}$, skimmer 1: $20 \mathrm{~V}$, skimmer 2: 10 $\mathrm{V}$, scan range: $50-1200 \mathrm{~m} / \mathrm{z}$. The flow rate was $0.63 \mathrm{~mL} \mathrm{~min}^{-1}$ and detection was at $360 \mathrm{~nm}$. Formic acid (p.a. 98-100\%), Milli-Q water and HPLC grade acetonitrile were used for gradient elution. Solvent A was water/formic acid /acetonitrile 87:10:3 (v/v/v); solvent B was water/formic acid/acetonitrile $40: 10: 50(\mathrm{v} / \mathrm{v} / \mathrm{v})$. The gradient starts linear at $6 \% \mathrm{~B}$ up to $30 \% \mathrm{~B}$ at 15 minutes, $50 \% \mathrm{~B}$ at 30 minutes, $60 \% \mathrm{~B}$ at 35 minutes and then down to $6 \% \mathrm{~B}$ at 41 minutes. This gradient was followed by a post-run time of 5 minutes at initial conditions.

The flavonols were quantified using a chromatographic system consisting in a quaternary LC-10ATVP pump, a FCV-10ALVP elution unit, a DGU-14A degassing unit, a CTO-10AVP column oven a SPD-10AVP UV/VIS detector, a SCL-10AVP controller, and a CLASS-VP data system, all from Shimadzu Corporation, Japan. The injection was performed manually with a Rheodyne injector model 7725i. The hydrolysis was carried out using a heated stir plate Corning, model PC-420.

The quantitative method by HPLC-DAD was based on the methodology developed by McDonald et al. ${ }^{17}$ with minor modifications. The separation was carried out on a reversed phase C-18 column (Shimpack VP ODS, $4.6 \mathrm{~mm}$, $150 \times 4.6 \mathrm{~mm}$, Shimadzu) at $40{ }^{\circ} \mathrm{C}$. The mobile phase consisted of water $\mathrm{pH}$ 2.5 adjusted with trifluoroacetic acid (mobile phase $\mathrm{A}$ ) and acetonitrile (mobile

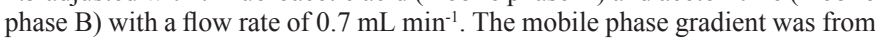
$18 \%$ to $40 \%$ of B in $20 \mathrm{~min}$, followed by an isocratic step of $5 \mathrm{~min}$, and a cleanup step of $100 \%$ B during 6 min. The equilibration time between injections was 10 min with $18 \%$ of B. The injection volume was $20 \mu \mathrm{L}$ and the detection was spectrophotometric $(365 \mathrm{~nm})$.

The sample treatment consisted in an acidic hydrolysis to quantify the total amount of each flavonol aglycone present in the wine samples, using the available commercial standards. Free flavonols were determined directly and the conjugated forms after acid hydrolysis of the wine samples $\left(90^{\circ} \mathrm{C}\right.$ over $2 \mathrm{~h}$ ) in $1.5 \mathrm{~N}$ hydrochloric acid $/ 50 \%$ methanol and $25 \mathrm{mgL}^{-1}$ with morin as internal standard. Working standard solutions, spanning the concentration range from 1 to $10 \mathrm{mgL}^{-1}$ of myricetin and 1 to $20 \mathrm{mgL}^{-1}$ of quercetin, were used for quantification purposes and concentrations between 0.5 to $5 \mathrm{mgL}^{-1}$ of rutin (quercetin-3-rutinoside) and quercitrin (quercetin-3-rhamnoside) were used for evaluation of the hydrolysis efficiency. These solutions were prepared by appropriate dilution of stock standard solutions in mobile phase A. The limits of detection (LOD) and quantification (LOQ) were obtained as three and ten times the noise signal from a chromatogram of a low concentration standard. This method considers the column efficiency and the matrix effect over the calculated limits, and is a suitable method for working concentrations that are above trace levels ${ }^{18,19}$. Method repeatability was obtained with a wine sample that was subdivided in three sub-samples and subjected to the methodology, with and without hydrolysis. The results of precision were expressed as RSD
(\%) of their respective areas. Accuracy was calculated for a red wine sample spiked with the studied flavonols. The error was determined as difference between the added and found concentration and was performed for hydrolysed and non-hydrolysed samples.

For classification purposes, classical discriminant analysis, principal components analysis ${ }^{20}$ and categorized graphs, such as scatter plots, were used. The latter were used to find relations between flavonol concentrations and establish ratios between them. All the statistical analyses were performed with the S-Plus 6.1 (Insightful Corp., USA) and STATISTICA 6.0 (StatSoft, Tulsa, OK, USA) software packages.

\section{Results and Discussion}

The identity assigned to flavonols found by HPLC-DAD-ESI-MS ${ }^{\mathrm{n}}$ analysis of Cabernet Sauvignon, Merlot and Carménère wines samples produced in Chile is summarized in Table 1. The analysis indicated that the main flavonols in these varieties are myricetin and quercetin together with their glycoside and glucoronide derivates (Fig. 3). These results are similar to the flavonol profiles of wines produced in Spain, France, Australia and Germany ${ }^{21,22}$. Although Cabernet Sauvignon, Merlot and Carménère wines present a very similar flavonol profile, there are some differences in the distribution between the aglycones and the glycosidic forms. This difference appears to be partially related to the stage of winemaking process ${ }^{23}$, but additionally also to compositional differences between varieties that could be useful for varietal differentiation. To eliminate the age of the wine as a factor, an acid hydrolysis was performed to quantify the total amount of each flavonol aglycone present in the wine samples, using the available commercial standards.

Table 1: Retention Times and Mass Spectral and UV-vis Data of Flavonols Identified in Cabernet Sauvignon, Merlot and Carmérère wines.

\begin{tabular}{|c|c|c|c|c|}
\hline Peak & Flavonol & $\begin{array}{c}\text { HPLC } \\
\mathbf{t}_{\mathbf{R}} \\
\text { (min) }\end{array}$ & $\begin{array}{c}\text { UV-vis } \\
\text { maxima } \\
\text { (nm) }\end{array}$ & $\begin{array}{c}\text { Molecular } \\
\text { and product } \\
\text { ions (m/z) }\end{array}$ \\
\hline $\mathbf{1}$ & $\begin{array}{c}\text { myricetin } \\
\text { 3-O-glucoronide }\end{array}$ & 13.8 & $236,249,349$ & 495,319 \\
\hline $\mathbf{2}$ & $\begin{array}{c}\text { myricetin } \\
\text { 3-O-glucoside }\end{array}$ & 14.4 & $240,250,354$ & 481,319 \\
\hline $\mathbf{3}$ & $\begin{array}{c}\text { quercetin } \\
\text { 3-O-glucoronide }\end{array}$ & 18.0 & $240,253,353$ & 479,303 \\
\hline $\mathbf{4}$ & $\begin{array}{c}\text { quercetin } \\
\text { 3-O-glucoside }\end{array}$ & 18.4 & $241,250,353$ & 465,303 \\
\hline $\mathbf{5}$ & $\begin{array}{c}\text { laricitrin } \\
\text { 3-O-glucoside }\end{array}$ & 20.5 & $234,249,350$ & 495,333 \\
\hline $\mathbf{6}$ & myricetin & 21.7 & $237,250,360$ & 319 \\
\hline $\mathbf{7}$ & $\begin{array}{c}\text { isorhamnetin } \\
\text { 3-O-glucoside }\end{array}$ & 23.6 & $238,248,355$ & 479,317 \\
\hline $\mathbf{8}$ & $\begin{array}{c}\text { syringetin } \\
\text {-O-glucoside }\end{array}$ & 24.2 & $237,250,330$ & 509,347 \\
\hline $\mathbf{9}$ & quercetin & 30.1 & $237,250,370$ & 303 \\
\hline $\mathbf{1 0}$ & laricitrin & 32.1 & 253,265, & 333 \\
\hline $\mathbf{1 1}$ & kaempferol & 37.2 & $237,249,366$ & 287 \\
\hline $\mathbf{1 2}$ & $\begin{array}{c}\text { isorhamnetin } \\
\mathbf{1 3}\end{array}$ & 41.1 & $240,252,370$ & 317 \\
\hline & syringetin & 41.5 & $240,251,370$ & 347 \\
\hline
\end{tabular}

In order to optimize the method for flavonol quantification, the hydrolysis conditions were evaluated using rutin and quercitrin as standards, especially rutin, since this is not found in wines ${ }^{22}$. The results showed that using $1.5 \mathrm{M}$ of hydrochloric acid for $2 \mathrm{~h}$, the efficiency of hydrolysis was at the maximum, without any important loss of free flavonols.

The relevant elements of the regression equation and other characteristic parameters of the method are presented in Table 2. The results show a good linear response for all studied flavonols; the precision of the methodology, obtained for a wine before and after hydrolysis, was sufficiently high for this type of analysis. 

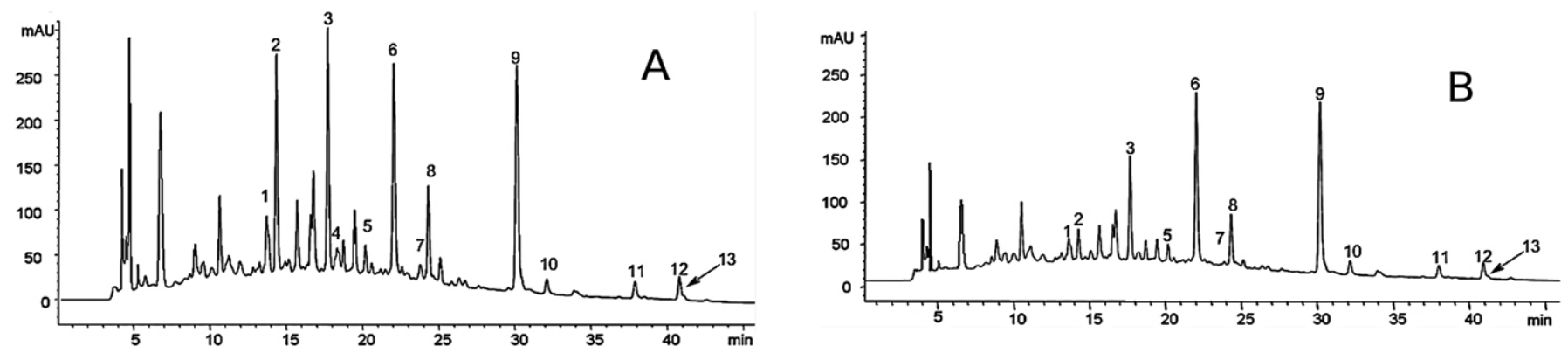
1

Figure 3: HPLC-DAD chromatogram of non hydrolysed wine flavonols at $365 \mathrm{~nm}$ for: A: Cabernet Sauvignon and B: Carménère. Peak identification in Table

Table 2: Elements of the regression equation and other characteristic parameters of the chromatographic method used for determination of flavonols.

\begin{tabular}{|c|c|c|c|c|c|c|c|}
\hline & Linear range & \multirow{2}{*}{$\mathrm{y}=\mathrm{b} \pm \mathrm{mx}$} & \multirow{2}{*}{$\mathrm{r}$} & $\mathrm{R}^{2}$ & \multirow{2}{*}{$S_{y / x}$} & \multirow{2}{*}{$\begin{array}{l}\text { RSD } \\
(\%)\end{array}$} & LOQ \\
\hline & $\left(\mathrm{mg} \mathrm{L}^{-1}\right)$ & & & $(\%)$ & & & $\left(\mathrm{mg} \mathrm{L}^{-1}\right)$ \\
\hline Rutin & $0.18-5.00$ & $y=0.0024+0.0878 x$ & 0.992 & 98.41 & 0.019 & 7.8 & 0.18 \\
\hline Quercitrin & $0.12-5.00$ & $y=-0.0092+0.0893 x$ & 0.997 & 98.80 & 0.016 & 6.0 & 0.12 \\
\hline Myricetin & $0.3-10.0$ & $y=0.028-0.2285 x$ & 0.990 & 98.69 & 0.070 & $0.7\left(8.8^{\mathrm{a}}\right)$ & 0.33 \\
\hline Quercetin & $0.3-20.0$ & $\mathrm{y}=0.0021+0.2079 \mathrm{x}$ & 0.995 & 99.24 & 0.630 & $4.5\left(7.3^{\mathrm{a}}\right)$ & 0.33 \\
\hline
\end{tabular}

$R^{2}$ : Coefficient of determination (obtained by ANOVA for validation of the model); RSD (\%): precision of method; LOQ: Limit of quantification; $y$ : AU/AUPI, $x: m g L^{-1} ;\left({ }^{a}\right)$ : obtained after hydrolysis.

Table 3: Accuracy of the determination of flavonols before and after hydrolysis.

\begin{tabular}{|c|c|c|c|c|}
\hline \multirow{2}{*}{ Added flavonol } & \multicolumn{2}{|c|}{ Concentration $\left(\mathrm{mg} \mathrm{L}^{-1}\right)$} & \multirow{2}{*}{ RSD\% } & $\begin{array}{c}\text { Recovery } \\
(\%)\end{array}$ \\
\cline { 2 - 4 } & Added & Found & & \\
\hline Rutin & 0.08 & 0.08 & 2.0 & 97.5 \\
\hline Quercitrin & 0.08 & 0.07 & 0.4 & 92.2 \\
\hline Myricetin & 0.42 & 0.41 & 4.1 & 97.9 \\
\hline Quercetin & 1.02 & 1.02 & 4.1 & 100.1 \\
\hline \multicolumn{5}{|c|}{ After hydrolysis } \\
\hline Myricetin & 0.42 & $0.42^{+}$ & 3.4 & 99.3 \\
\hline Quercetin & 1.02 & $1.03^{+}$ & 4.5 & 100.7 \\
\hline
\end{tabular}

t: Found concentration was determined as the difference between the quantified concentration by the method and the previously determined natural concentration; $n: 3$.

The accuracy evaluation results, shown in Table 3, indicate that the obtained recovery is very close to $100 \%$ in all cases. The proposed method can be used to quantify the flavonols of interest between 0.12 to $20 \mathrm{mgL}^{-1}$ in red wine.

The present study only considered the major flavonols in wine, quercetin and myricetin as well as their conjugated forms, for quantification purposes because the peaks of the other minor flavonols (syringetin, laricitrin, isorhamnetin and kaempferol in their free and conjugated forms) were not quantifiable in all wine samples. The concentrations were expressed as the sum of total myricetin + total quercetin $(\mathrm{TM}+\mathrm{TQ})$ and the difference of these parameters were evaluated in function of wine variety. Descriptive statistics for flavonol concentrations in Carménère, Merlot and Cabernet Sauvignon wines (Table 4 ) show that the mean concentration of TM + TQ is similar $(\alpha=0.05)$ for Carménère $\left(81.5 \mathrm{mgL}^{-1}\right)$ and Merlot wines $\left(78.9 \mathrm{mgL}^{-1}\right)$, and it is significantly higher $(\alpha=0.05)$ in both varieties in comparison with Cabernet Sauvignon wines $\left(53.9 \mathrm{mgL}^{-1}\right)$. However, a very broad variation was observed for each of the three varieties (Fig. 4), ranging from 14.4 to $171.3 \mathrm{mgL}^{-1}$ of TM + TQ for Carménère, from 17.9 to $149.5 \mathrm{mgL}^{-1}$ for Merlot and between 10.2 and 160.0 $\mathrm{mgL}^{-1}$ for Cabernet Sauvignon.

The mean levels of TM+ TQ found in Carménère and Merlot wines were higher than most data reported in the literature for Cabernet Sauvignon, Merlot and other varieties of wines produced in different countries, including Chile ${ }^{17,24}$, Italy ${ }^{25}$ and Bulgaria ${ }^{26}$, and was surpassed only by the mean concentration of ultrapremium Cabernet Sauvignon wines produced in California $(98.1 \mathrm{mgL}-$ $1)^{27}$, although not by the high volume Cabernet Sauvignon wines produced in California $\left(31.5 \mathrm{mgL}^{-1}\right)$. The authors attribute this to: 1) different maceration techniques, leading to more efficient recovery in the wine, or 2) that the different grapes used for the ultrapremium wines. In the present work, a Carménère wine produced in the Rapel valley, vintage 2003, presented the maximum individual concentration of TM + TQ $\left(171.3 \mathrm{mgL}^{-1}\right)$, followed by one of Cabernet Sauvignon (160.0 mgL-1 Maule valley, 2003) and one of Merlot (149.5 mgL Maipo valley, 2003). Fifteen percent of Chilean Carménère samples, $11.4 \%$ of Merlot, and one sample of Cabernet Sauvignon surpassed the maximum level of $117.4 \mathrm{mgL}^{-1}$ for TM+ TQ, which was found in the reviewed literature for any individual wine, independently of its variety and origin. It is well known, that compounds other than flavonols, such as resveratrol, anthocyanins, flavan-3ols and phenolic acids, contribute to the antioxidant activity of red wine ${ }^{24,27}$ but the present results confirm, based on a significantly broader number of samples, that TM + TQ concentrations of red wines produced in Chile in most cases surpass those of other origin. Additionally, this observation could be explained because the analysed wines were young wines and were analysed in the same year of their production. 
Table 4: Descriptive statistics for flavonol concentrations in Carménère, Merlot and Cabernet Sauvignon wines, vintages 2002 and 2003 , Chile

\begin{tabular}{|c|c|c|c|c|c|c|c|c|c|c|c|c|c|c|c|c|c|c|}
\hline \multicolumn{7}{|c|}{ Carménère } & \multicolumn{6}{|c|}{ Merlot } & \multicolumn{6}{|c|}{ Cabernet Sauvignon } \\
\hline & $\mathrm{n}$ & $\bar{x}^{+}$ & $\mathrm{Me}^{+}$ & $\operatorname{Min}^{+}$ & $\operatorname{Max}^{\dagger}$ & $s^{+}$ & $\mathrm{n}$ & $\bar{x}^{+}$ & $\mathrm{Me}^{+}$ & $\operatorname{Min}^{+}$ & $\operatorname{Max}^{+}$ & $\mathrm{s}^{\dagger}$ & $\mathrm{n}$ & $\bar{x}^{+}$ & $\mathrm{Me}^{+}$ & $\operatorname{Min}^{+}$ & $\operatorname{Max}^{+}$ & $\mathrm{s}^{\dagger}$ \\
\hline FM & 58 & 12.3 & 11.9 & 1.2 & 21.1 & 4.3 & 50 & 6.6 & 6.1 & 1.9 & 18.1 & 3.2 & 140 & 9.6 & 8.3 & 0.9 & 36.1 & 5.2 \\
\hline FQ & 58 & 17.8 & 18.6 & 0.8 & 37 & 8.5 & 50 & 20.9 & 21.4 & 4.3 & 48.4 & 9.7 & 140 & 14.9 & 14.7 & 0.7 & 42.9 & 8.2 \\
\hline TM & 40 & 37.8 & 38.6 & 10 & 70.4 & 13.2 & 35 & 26.1 & 25.5 & 7.9 & 49.3 & 9.3 & 108 & 22.7 & 20.3 & 4.4 & 87 & 10.8 \\
\hline TQ & 40 & 43.7 & 42.5 & 4.4 & 100.8 & 20.1 & 35 & 52.8 & 52.6 & 10 & 105.5 & 23.3 & 108 & 31.2 & 30.8 & 5.5 & 73 & 13.6 \\
\hline $\mathrm{CM}$ & 40 & 26.6 & 26.9 & 3.8 & 55.2 & 13.1 & 35 & 19.5 & 20.6 & 0.7 & 44 & 9.4 & 108 & 13.7 & 11.1 & 1.5 & 50.9 & 8.6 \\
\hline CQ & 40 & 24.7 & 23.1 & 1.2 & 64.5 & 14.3 & 35 & 32.2 & 33.2 & 4.8 & 76.6 & 17.6 & 108 & 15.3 & 12.6 & 1.4 & 51.7 & 10.2 \\
\hline $\mathrm{TM}+\mathrm{TQ}$ & 40 & 81.5 & 75 & 14.4 & 171.3 & 32.4 & 35 & 78.9 & 78.9 & 17.9 & 149.5 & 31.5 & 108 & 53.9 & 51.3 & 10.2 & 160 & 22.8 \\
\hline
\end{tabular}

Note: $n$ : Sample sizes; $\bar{x}$ : mean; Me: median; Min: minimum value; Max: maximum value and

s: Standard deviation; FM: free myricetin; FQ: free quercetin; TM: total myricetin;

$T Q$ total quercetin; CM: conjugated myricetin; $C Q$ : conjugated quercetin; $\uparrow:\left(\mathrm{mg} \mathrm{L}^{-1}\right)$.

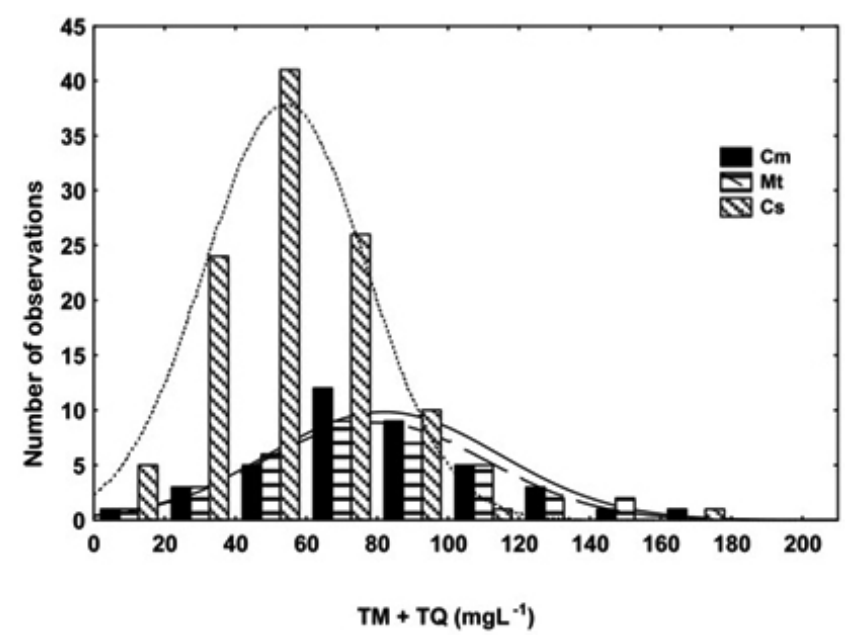

Figure 4: Histograms Total Myricetin + Total Quercetin (TM+TQ) concentrations in Carménère, Merlot and Cabernet Sauvignon wines, vintages 2002 and 2003, Chile. Cm: Carménère; Mt: Merlot; Cs: Cabernet Sauvignon

In Fig. 4, it can be clearly observed that even if there is a difference of the mean and median concentrations of TM+TQ between Cabernet Sauvignon and Merlot or Carménère, the overlapping of the concentrations of the three varieties show that this is not an appropriate parameter to differentiate between wines of these three varieties according to their $\mathrm{TM}+\mathrm{TQ}$ concentration.

As shown in Table 4, Carménère also presented the highest mean concentration $\left(12.3 \mathrm{mgL}^{-1}\right)$ for free myricetin, followed by Cabernet Sauvignon $\left(9.6 \mathrm{mgL}^{-1}\right)$ and Merlot $\left(6.6 \mathrm{mgL}^{-1}\right)$, whereas mean free quercetin concentration was higher in Merlot $\left(20.9 \mathrm{mgL}^{-1}\right)$, followed by Carménère $\left(17.8 \mathrm{mgL}^{-1}\right)$ and Cabernet Sauvignon $\left(14.9 \mathrm{mgL}^{-1}\right)$.

For conjugated flavonols, mean myricetin levels were higher in Carménère $\left(26.7 \mathrm{mgL}^{-1}\right)$, followed by Merlot $\left(19.5 \mathrm{mgL}^{-1}\right)$ and Cabernet Sauvignon, whereas the mean quercetin concentrations were higher in Merlot (32.2 $\left.\mathrm{mgL}^{-1}\right)$, followed by Carménère and Cabernet Sauvignon $\left(12.6 \mathrm{mgL}^{-1}\right)$.

To evaluate their discriminating power between Cabernet Sauvignon, Carménère and Merlot varieties, the concentrations of flavonols were submitted to an analysis of variance. Results are summarized in Table 5, where the second column gives p-values for differences between any of the grape varieties, whereas the remaining three columns provide results for pair-wise comparisons. Bold numbers indicate statistical significance at the $99 \%$ confidence level. As can be observed, most flavonols show significant difference between Cabernet Sauvignon and Merlot or Carménère, but only the different forms of myricetin show significant differences between Merlot and Carménère.
Table 5: P-values of Analyses of variance comparing mean concentration of flavonols in Cabernet Sauvignon (Cs), Merlot (Mt) and Carménère (Cm).

\begin{tabular}{|l|c|c|c|c|}
\hline \multirow{2}{*}{\multicolumn{1}{c|}{ Flavonols }} & \multirow{2}{*}{$\begin{array}{c}\text { ANOVA } \\
p \text {-value }\end{array}$} & \multicolumn{3}{|c|}{ Pair wise comparison p-values } \\
\cline { 3 - 5 } & $\begin{array}{c}\mathrm{Cm}- \\
\mathrm{Mt}\end{array}$ & $\mathrm{Cm}-\mathrm{Cs}$ & $\mathrm{Mt}-\mathrm{Cs}$ \\
\hline Free Myricetin & $<.001$ & $<.001$ & $<.001$ & $<.001$ \\
\hline Free Quercetin & $<.001$ & .146 & .082 & $<.001$ \\
\hline Total Myricetin (TM) & $<.001$ & $<.001$ & $<.001$ & .247 \\
\hline Total Quercetin (TQ) & $<.001$ & .060 & $<.001$ & $<.001$ \\
\hline Conjugated Myricetin & $<.001$ & $\mathbf{. 0 0 6}$ & $<.001$ & $\mathbf{. 0 0 7}$ \\
\hline Conjugated Quercetin & $<.001$ & .032 & $<.001$ & $<.001$ \\
\hline TM + TQ & $<.001$ & .911 & $<.001$ & $<.001$ \\
\hline
\end{tabular}

To evaluate the potential of the different forms of myricetin to discriminate between these three wine varieties, especially Carménère from Merlot, the distribution of this flavonol concentration was explored. As illustrated in Fig. 5, the concentration ranges of free myricetin in the three varieties show substantial overlap. The use of the concentration of free myricetin alone does not enable the differentiation between grape varieties, and the distinction between Merlot and Carménère is the most difficult. Different combinations and relations between flavonols must be evaluated for their specific discriminating power between Carménère and Merlot.

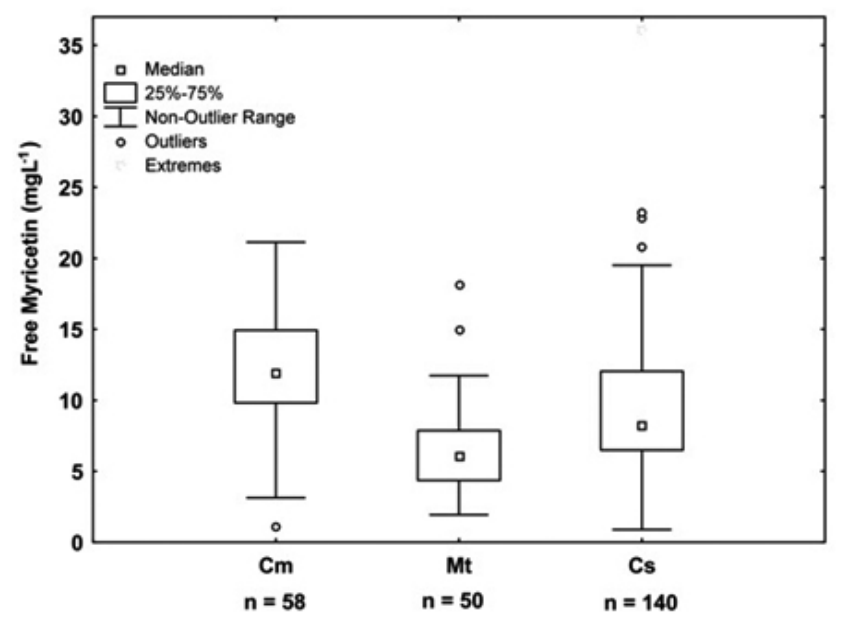

Figure 5: Boxplots for free myricetin concentrations in Carménère $(\mathrm{Cm})$, Merlot (Mt) and Cabernet Sauvignon (Cs), vintages 2002 and 2003.

A Principal Component Analysis (PCA) was carried out to evaluate the discriminating power of the combination of several flavonols to differentiate between the varieties Carménère and Merlot, which is the main objective since the varietal differentiation of Cabernet Sauvignon is already achieved ${ }^{9}$. The variables included in this analysis were free myricetin, free quercetin, total 
myricetin, total quercetin (considering that after hydrolysis several conjugates could be freed to contribute to the total concentration of flavonol) and the ratio between total myricetin and total quercetin (TQ/TM). The first two components, explain an $86 \%$ of the variability in the original data. The principal components analysis scores (Fig. 6) show that the Carménère and Merlot wine samples are mainly separated by factor 2 . The loadings analysis shows that high values of the TQ/TM ratio and free myricetin concentration have more weight over the separation with the second principal component (Fig. 6). From this analysis, it was observed that the most promising alternatives for discriminating between Carménère and Merlot are the ratio TQ/TM, free myricetin concentration, followed by the total concentration of quercetin and myricetin.
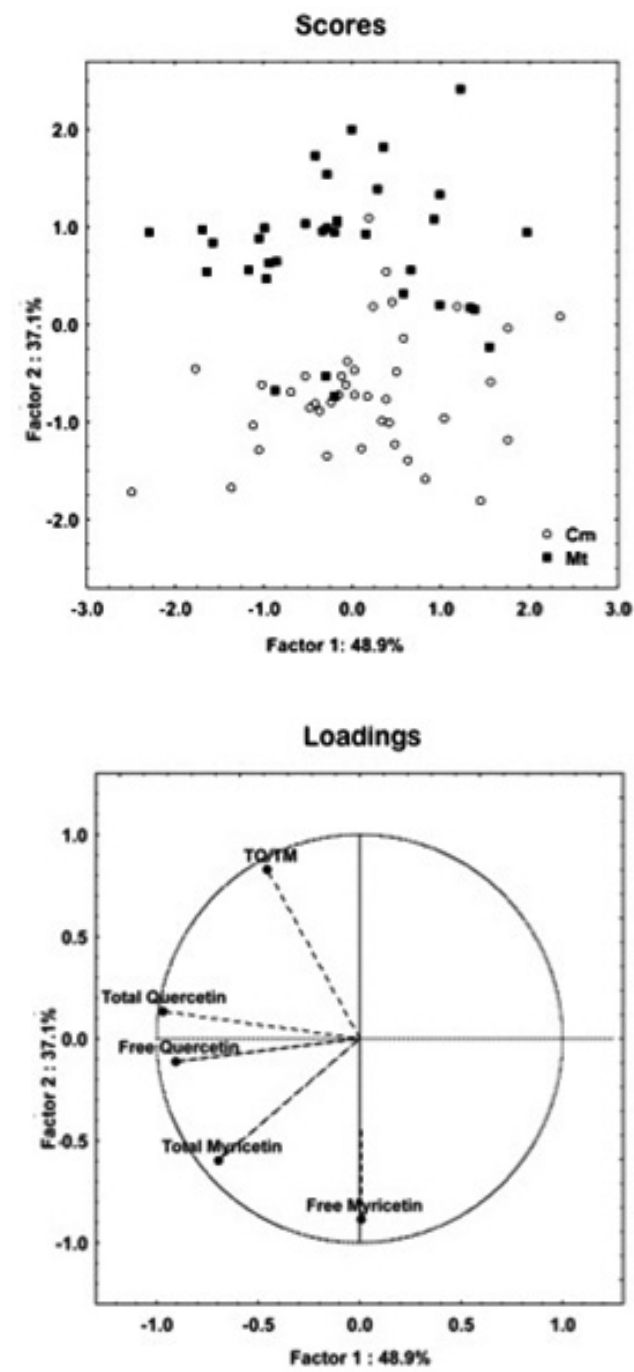

Figure 6: Scores and Loadings of principal components analysis in Merlot and Carménère.

The relation between the total concentrations of quercetin (TQ) and myricetin (TM) (Fig. 7) accomplishes some separation, but the inclusion of the TQ/TM ratio with free myricetin concentration gives a better separation between Merlot and Carménère (Fig. 8). Some misclassification still occurs, and this could be due to some true Carménère samples still being declared as Merlot by producers, due to history of Carménère in Chile.

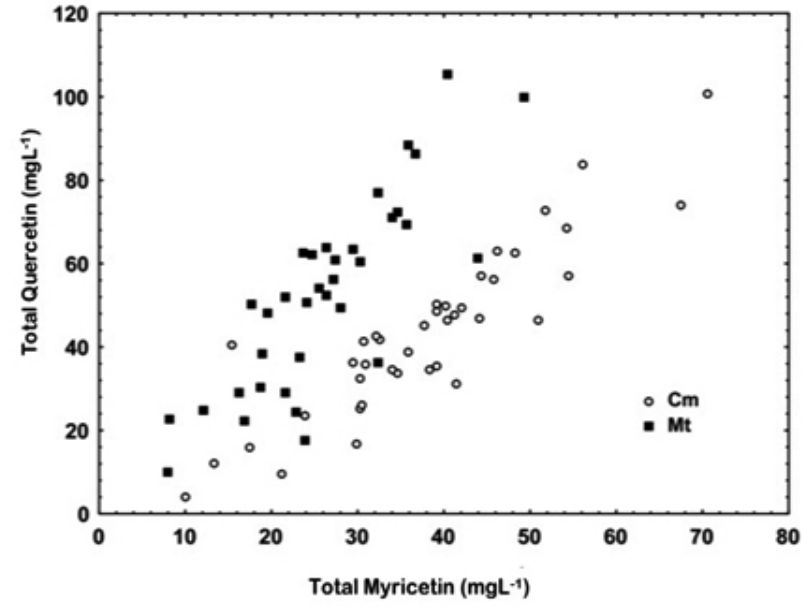

Figure 7: Relation between total myricetin and total quercetin concentrations in Carménère and Merlot, vintages 2002 and 2003.

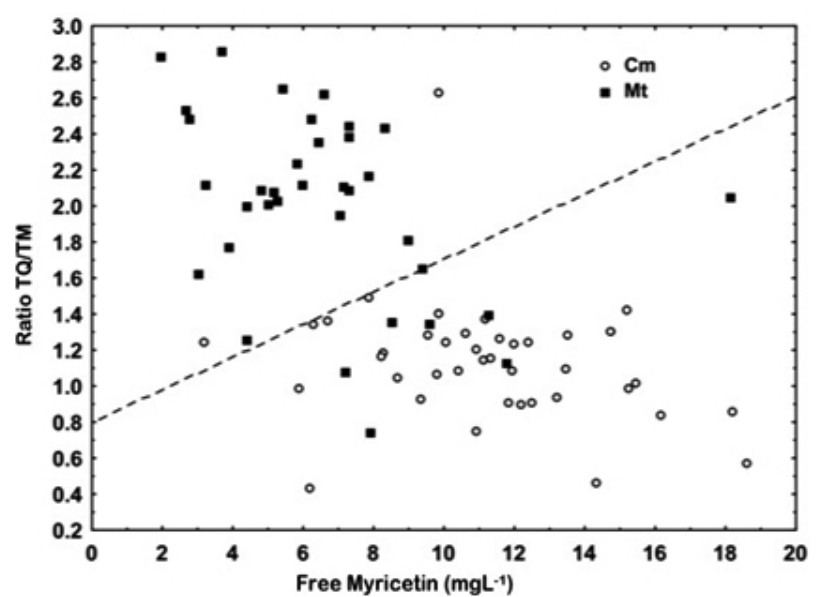

Figure 8: Relation between free myricetin concentration and the ratio TQ/ TM in Merlot and Carménère wines, vintages 2002 and 2003.

To estimate the classification error rate using the same chemical markers included in the principal components analysis, a linear discriminant analysis was performed (Table 6). The results show a classification error for Carménère of only $2.5 \%$ (1 sample) and for Merlot of $11.4 \%$ (4 samples).

Table 6: Empirical classification using linear discriminant analysis.

\begin{tabular}{|c|c|c|c|}
\hline & Carménère & Merlot & Error \\
\hline Carménère & 39 & 1 & $2.5 \%$ \\
\hline Merlot & 4 & 31 & $11.4 \%$ \\
\hline \multicolumn{3}{|c|}{ Total error $6.7 \%$} \\
\hline
\end{tabular}

Of the two clusters found in the data exploration analysis, corresponding to Carménère and Merlot groups, some misclassification still occurs and could be due to some true Carménère samples still being declared as Merlot by producers. Using SSR DNA markers to confirm the varietal identity ${ }^{2}$, four of a total of 93 vines from five Chilean vineyards, originally planted as Merlot, were found to match Carménère.

The error rates obtained with linear discriminant analysis were somewhat more favourable than those observed by linear discriminant analysis of the anthocyanin profiles when relating the proportion of peonidine-3-glucoside to the ratio of $\mathrm{TM} / \mathrm{TQ}^{9}$.

\section{CONCLUSIONS}

The analysed wines presented mean levels of total flavonols higher than most previously reported values in the literature for Cabernet Sauvignon or 
Merlot wines produced in different countries. The values were only surpassed by ultrapremium Cabernet Sauvignon wines produced in California, although not by Cabernet Sauvignon high volume wines from this origin.

With respect to the varietal differentiation of wines, the sum of total myricetin and total quercetin (TM+TQ) was very useful. Although Carménère and Merlot wines presented higher mean concentrations than Cabernet Sauvignon, the overlapping of the concentrations of the three varieties shows that this is not an appropriate parameter for wine differentiation. However, the ratio of total quercetin/total myricetin combined with the concentration of free myricetin appears as a more promising tool to differentiate between Carménère and Merlot wines in order to verify the varietal authenticity of wines, , and especially Carménère, which is presently promoted as Chile's own signature grape.

The occurring misclassification could be because some producers still declare true Carménère samples as Merlot. Consequently, those vineyards declared as Carménère correspond to this variety, but a certain percentage of vineyards declared as Merlot still correspond to Carménère and should be reevaluated by ampelography as well as by modern DNA methods.

\section{ACKNOWLEDGEMENTS}

The authors thank FONDEF-Chile (Grant No. D00I1138), the Consorcio Tecnológico Vinnova (Grant 05 CTE 01-07), the participating Chilean Wineries for their financial support and interest, the Shimadzu Corporation for providing a complete HPLC-DAD system for the study, the Graduate School, Universidad de Concepción for the Doctoral Fellowship for Carola Vergara, and CONICYT for the Doctoral Fellowship for Luis Gutiérrez.

\section{REFERENCES}

1. J.M. Boursiquot, P. Parra, Riv. Vtic. Enol. 1, 41, (1996)

2. P. Hinrichsen, C. Narvaez, J.E. Bowers, J.M. Boursiquot, J. Valenzuela, C. Muñoz, C.P. Meredith, Am. J. Enol. Vitic. 52, 396, (2001)

3. K. Fernandez, J.A. Kennedy, E. Agosín, J. Agric. Food. Chem. 55, 3675, (2007)

4. Wines of Chile (2009), Wines of Chile website, http://www.winesofchile. org/the-wines/wine-varieties/carmenere/

5. R. Eder, S. Wendelin, J. Barna, Mitt. Klosterneuburg 44, 201, (1994)

6. B. Holbach, R. Marx, M. Ackermann, Lebensmittelchemie 51, 78, (1997)

7. H. Otteneder, R. Marx, M. Zimmer, Aust. J. Grape Wine Res. 10, 3, (2004)

8. B. Holbach, R. Marx, M., Zimmer, Lebensmittelchemie, 55, 32, (2001)

9. D. von Baer, C. Mardones, L. Gutiérrez, G. Hofmann, A. Hitschfeld, C. Vergara in Authentication of Food and Wine, S.E. Ebeler, G.R. Takeoka, P. Winterhalter eds. ACS Symp. Ser. $\mathrm{N}^{\circ}$ 952, Washington, D.C. 2007; pp. 228-238.

10. Yonekura-Sakakibara, K. Tohge, T. Niida, R. Saito, K. J. Biol. Chem. 282, 14932, (2007)

11. Ono, E. Homma, Y. Horikawa, M. Kunikane-Doi, S. Imai, H. Takahashi,S. Kawai,Y. Ishiguro,M. Fukui,Y. Nakayamab, T. Plant Cell, 22, 2856, (2010)

12. Offen, W. Martinez-Fleites, C. Yang, M. Kiat-Lim, E. Davis, B.G. Tarling, C.A. Ford, C.M. Bowles, D.J. Davies, G.J. EMBO J. 25, 1396, (2006)

13. D. Makris, S. Kallithrakab, P. Kefalasa, J. Food Compos. Anal. 19, 396, (2006)

14. K.L. Wolfe, R.H. Liu, J. Agric. Food. Chem. 56, 8404, (2008)

15. Nassiri-Asl, M. and Hosseinzadeh, N. Phytother. Res. 23, 1197, (2009)

16. A.W. Boots, G. Haenen, A. Bast, Eur. J. Pharmacol. 585, 325, (1999)

17. M. McDonald, M. Hughes, J. Burns, M.E.J. Lean, D. Matthews, A. Crozier, J. Agric. Food. Chem. 50, 4096, (1998)

18. C.M. Riley in Progress in pharmaceutical and biomedical analysis, volume 3: Development and validation of analytical methods. C.M. Riley, T.W. Rosanske eds, Pergamon, 1996; pp. 15-71.

19. Corley, J. in Best practices in establishing detection and quantification limits for pesticide residues in foods, Handbook of Residue Analytical Methods for Agrochemicals. Dr Philip W Lee ed, John Wiley \& Sons Ltd., 2003; pp. 59-74.

20. D.F. Morrison, Multivariate statistical methods, McGraw - Hill: New York, 1990.

21. N. Castillo-Muñoz, S. Gómez-Alonso, E. García-Romero I. HermosínGutiérrez, J. Agric. Food. Chem. 55, 992, (2007)

22. D.W. Jeffery, M. Parker, P.A. Smith, Aust. J. Grape Wine Res. 14, 153, (2008)

23. M.S. García-Falcón, C. Pérez-Lamela, E. Martínez-Carballo, J. Simal-
Gándar, Food Chem. 105, 248, (2007)

24. J. Burns, PT. Gardner, J. O'Neil, S. Crawford, I. Morecroft, D.B. McPhail, C. Lister, D. Matthews, M.R. MacLean, M.E.J. Lean, G.G. Duthie, A. Crozier, J. Agric. Food. Chem. 48, 220, (2000)

25. L. Gambelli, G.P. Santaroni, J. Food Compos. Anal. 17, 613, (2004)

26. S. Tsanova-Savova, F. Ribarova, J. Food Compos. Anal. 15, 639, (2002)

27. J.G. Ritchey, A.L. Waterhouse, Am. J. Enol. Vitic. 50, 91, (1999) 